\title{
Waist circumference, body mass index and employment outcomes
}

\section{Jonas Minet Kinge}

Norwegian Institute of Public Health and

Department of Health Management and Health Economics,

University of Oslo

\section{UNIVERSITY}

OF OSLO

HEALTH ECONOMICS

RESEARCH NETWORK

Working paper 2016: 4

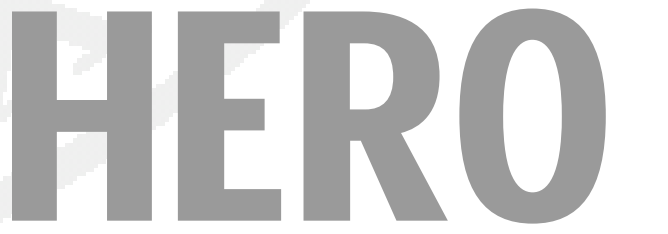




\section{Waist circumference, body mass index and employment outcomes ${ }^{a}$}

Jonas Minet Kinge (Jonas.Minet.Kinge@fhi.no)

Department of Health Statistics, Norwegian Institute of Public Health, Norway

Department of Health Management and Health Economics, University of Oslo, Norway

JEL: I00, I12, J24

Keywords: waist circumference; body mass index; obesity; employment status

\section{ABSTRACT}

Body mass index (BMI) is an imperfect measure of body-fat and recent studies provides evidence in favour of replacing BMI with waist circumference (WC). Hence, I investigate how WC and BMI are associated with employment status in England. I use fifteen rounds of the Health Survey for England (1998-2013), which has measures of employment status in addition to measured height, weight and WC. WC and BMI were entered as continuous variables and obesity as binary variables defined using both WC and BMI. I used multivariate models controlling for a set of covariates. I found significant and negative associations between both WC and BMI with employment in women. In men, the coefficient of WC was significant, but not BMI. In both men and women my findings suggest that the association of WC with employment was of greater magnitude, than the association between BMI and employment. To explore whether any difference in the association was mitigated by conventional instrumental variables methods I reran the analysis using the "workhorse" in analyses of BMI and employment. I.e. instrumenting for WC and BMI based on WC and BMI of a biological family member. Significant endogeneity was detected for both WC and BMI. The finding, that the impact of WC on employment was larger than BMI, did not persist in the IV-models. Although the IV models found significant impacts of obesity on employment, they were not more pronounced when WC was used to measure obesity, compare to BMI.

\footnotetext{
a I would like to acknowledge the project « The burden of obesity in Norway: morbidity, mortality, health service use and productivity loss» funded by the Norwegian Research Council through grant 250335/F20. I also thank Laura Vallejo-Torres, Apostolos Davillas and Per Arne Holman for helpful comments.
} 


\section{Introduction}

The impact of body fat on employment is of increasing interest as obesity and overweight have increased sharply in recent decades. Worldwide, the proportion of men who were overweight, as measured by Body Mass Index (BMI), increased from 29\% in 1980 , to $37 \%$ in 2013 , and the proportion of women who were overweight increased from $30 \%$ to $38 \%$ (Ng et al., 2014). The prevalence of obesity, measured by BMI, has also increased in England and trend data from the Health Survey for England (HSE) has shown obesity rising from $13 \%$ of men and $16 \%$ of women in 1993 to $26 \%$ of men and $24 \%$ of women in 2013 (Moody, 2014). In addition, studies that use other measures of body fat than BMI suggests that these trends might be underestimated. For example, Elobeid et al. (2007); Ford et al. (2014) have shown that over the last 50 years waist circumference (WC) values have increased beyond those expected from BMI increases.

These trends might have severe labour market consequences for a number of reasons. First, obesity is a debilitating health condition associated with a wide number of diseases, which may preclude the ability to work (NHLBI Obesity Education Initiative, 1998, Kinge and Morris, 2010). Second, obesity may have an impact on certain characteristics, like self-esteem, that might reduce performance in the labour market (Komlos et al., 2004, Offer, 2001). Third, there may be discrimination against the obese due prejudice and stereotyping by employers (McLean and Moon, 1980, Everett, 1990, Pagan and Davila, 1997, Rooth, 2009). However, it is intrinsically difficult to establish the impact of obesity on employment status due to the following classic endogeneity issues: a) Simultaneity in that employment status might affect obesity. b) Omitted variable bias in that unobserved variables, such as time preference (Komlos et al., 2004), have an impact on both obesity and employment.

Finally, c) measurement error might be important and a number of authors discuss this in studies where self-reported (rather than measured) height and weight are used to classify individuals as obese (O'Neill and Sweetman, 2013). However, obesity is a concept that refers to excessive fatness (Bjorntorp et al., 2002) and a number of studies also find that Body Mass index (BMI), even when based on measured height and weight, results in important misclassification of individuals into obesity categories (Cawley, 2015, O'Neill, 2015). This might be caused BMI being unable to distinguish fat from 
muscle, bone and other lean body mass (Burkhauser and Cawley, 2008, O'Neill, 2015, Johansson et al., 2009), which makes BMI a noisy measure of fatness. The misclassification leads to concerns about potential underestimation of the consequences of high fat mass (Kragelund and Omland, 2005, Burkhauser and Cawley, 2008, Johansson et al., 2009, Mosca, 2013, O’Neill, 2015).

Because of the shortcomings in BMI, a World Health Organisation expert consultation on obesity drew attention to the need for other indicators to complement the measurement of BMI (WHO, 2000). Consequently, a number of alternative measures have been proposed. These include percent body fat estimated using bioelectrical impedance analysis (BIA), measures based on WC and Waist to Hip ratio. A recent study by O'Neill (2015) provides strong support for using WC to classify obesity. By using BMI, WC and BIA to measure obesity he found that WC was superior at classifying obesity. In contrast to BMI and BIA, the classification of obesity based on WC exhibited high degrees of accuracy in terms of sensitivity and specificity (O’Neill, 2015).

The aim of current analysis is to use an arguably more accurate measure of obesity, WC, to study the consequences of fatness on employment outcomes. In addition to more correctly classifying people as obese, the impact of WC (compared with BMI) on employment may differ for a number of reasons. Firstly, it has greater support in the medical literature as it been found that WC outperforms BMI in predicting the health risks associated with obesity (Janssen et al., 2004). Second, WC is a stronger predictor of all-cause mortality than BMI (Seidell, 2010). Third, WC is the anthropometric measure that best predicts the distribution of adipose tissue (Chan et al., 2003). Forth, it is a 'visible' measure of fatness, which might be interpreted by employers, customers or coworkers as an unattractive physical attribute, and thus affect the probability of employment (Johansson et al., 2009).

To examine the impact WC and BMI on employment I used data from fifteen rounds of the Health Survey for England (HSE). I used multivariate models controlling for a set of covariates and instrumental variable models. I instrumented WC, BMI and obesity using genetic variation in weight: the mean WC/BMI of the oldest biological child. This is positively correlated with parent's obesity. However, there might be potential challenges 
with fulfilling the second requirement for an instrument, which is that it should not itself be correlated with the error term in the employment equation. Hence, the potential pitfalls with the instrument and how these are mitigated are discussed below.

\subsection{Related literature}

Several studies have previously analysed the effect of obesity measured by BMI on employment outcomes (Kelly, 2014). For example in the US (Burkhauser and Cawley, 2008, Cawley, 2004, Cawley, 2000a, Norton and Han, 2008, Sabia and Rees, 2012, Renna and Thakur, 2010, Averett and Korenman, 1996, Wada and Tekin, 2010); Canada (Larose et al., 2016); China (Shimokawa, 2008); Denmark (Greve, 2008); Finland (Johansson et al., 2009, Sarlio-Lähteenkorva and Lahelma, 1999); Germany (Bozoyan and Wolbring, 2011); Iceland (Asgeirsdottir, 2011); Sweden (Rooth, 2009, Lundborg et al., 2014). In addition, there are a number of cross country studies in Europe (Garcia and Quintana-Domeque, 2007, Brunello and d'Hombres, 2007, Atella et al., 2008, Villar and Quintana-Domeque, 2009). The results generally indicate poorer labour market outcomes for obese women, while the results for men are more mixed.

Two studies use UK data and instrumental variables. Morris (2007) uses two rounds of the HSE (1997 and 1998) to investigate the impact of obesity on employment (measured as a binary variable). Using both univariate probit and IV regression models it was shown a statistically significant negative effect of obesity on employment in both men and women. To instrument individual obesity an area level obesity measure was used: the prevalence of obesity in the area in which the respondent lives. Lindeboom et al. (2010) study the effect of obesity on employment (measured as a binary variable), using data from the British National Child Development Study. The results show a significant negative association between obesity and employment in both men and women. However, in their IV-regression models, using parental obesity as instruments, the associations were no longer significant.

To account for simultaneity and omitted variable bias the studies discussed above have used econometric techniques like instrumental variable techniques, time-fixed effects and sibling-fixed effects. However, surprisingly little focus has been on handling measurement error related to the use of BMI for measuring obesity. 
Four studies included alternative measures of fatness and studies its impact on employment (Mosca, 2013, Johansson et al., 2009, Burkhauser and Cawley, 2008, Wada and Tekin, 2010). Only two of these have used WC. Mosca (2013) compares the associations between BMI, WC and employment (measured as a binary variable) in older Irish (aged 50+) individuals using a standard probit model. In women, employment probability was significant and negatively associated with both BMI and WC (entered linearly). However, the employment elasticity was larger for WC than for BMI. In men no significant associations with employment were found when BMI and WC were entered linearly. In both genders, significant and negative associations were found between employment and obesity as a categorical variable, defined using both BMI and WC. A study by Johansson et al. (2009), examined the associations between obesity and employment (measured as a binary variable) in Finland using BMI, WC and BIA. All measures of obesity were significant and negatively associated with employment status in women, and BIA was significant and negatively associated with men's employment status. When categorical measures of obesity were used, all three measures were significant in both men and women. However, Johansson et al. (2009) argues that conclusions based WC may differ from conclusions reached by BMI.

Although the studies by Mosca (2013) and Johansson et al. (2009) have used WC to mitigate measurement error related to BMI, they have not tried to account for simultaneity and omitted variable bias by for example instrumental variables. In addition, they have not estimated values that allow direct comparison of the effect of the coefficients of WC and BMI on employment. My paper is the first attempt to combine the most recent knowledge on measuring obesity using WC, with instrumental variable techniques. In addition, I express the coefficients of WC and BMI using methods that allow for direct comparisons of their magnitude.

\section{Data and variables}

\subsection{Data source}

The analysis was based on data from sixteen rounds (1998-2013) of the Health Survey for England (HSE) (National Centre for Social Research and Department of Epidemiology 
and Public Health University College London (UCL), 1997 - 2012); 2013 is the most recent year of data available. The HSE is a repeated cross-sectional survey which draws a different sample of nationally representative individuals living in England each year. The sample was selected using a multi-stage stratified probability sampling design with postcode sectors selected at the first stage and household addresses within postcode sectors selected at the second stage. Stratification was based on geographical areas and not on individual characteristics.

Data from year 2000 was excluded, due to missing values on WC in the population below the age of 65 . All adults (16+) within the household (up to a maximum of 10 ) were eligible for interview, plus up to 2 children (0-15). The interviewer randomly selected the children to interview in a household with more than 2 children. For children aged 012 , parents answered on behalf of the child but the child was present.

\subsection{Employment outcome}

The employment status was defined using the activity status for last week. I measure employment status as a binary variable taking the value one if an individual was employed and zero otherwise.

\subsection{BMI, WC and obesity measures}

HSE contains height and weight values for all individuals aged 2 and over and waist circumference in those aged 11 and over. One useful feature of the HSE is that the WC and BMI values are not self-reported, which reduces the likelihood of measurement error. Both height and weight were measured at the interview. WC was measured by a specially trained nurse two times, and a third measurement was taken if the difference between the two first measurements was more than $3 \mathrm{~cm}$.

I use two measures of obesity, based on BMI and on WC. Obesity measured by BMI was defined according to World Health Organization guidelines (World Health Organization, 1995). I measure obesity as a binary variable taking the value one if an individual has a $\mathrm{BMI} \geq 30 \mathrm{~kg} / \mathrm{m}^{2}$ and zero otherwise. 
Men are classified as being at "high risk" of obesity if their waist circumference exceeds $102 \mathrm{~cm}$, while for women the threshold is $88 \mathrm{~cm}$ (Lean et al., 1995, Lear et al., 2010, National Heart Lung and Blood Institute (NHLBI), 2000) and this definition has been used by others who compare obesity defined by BMI and WC (O'Neill, 2015, Johansson et al., 2009). I measure obesity as a binary variable taking the value one if an individual has a WC $>102 \mathrm{~cm}$ (men) and WC > $88 \mathrm{~cm}$ (women) and zero otherwise.

BMI and WC were entered as continuous variables and obesity as a binary variable defined using both BMI and WC.

\subsection{Covariates}

I include the following covariates in each regression: age (quadratic function); marital status (married/cohabitees/non-married); education qualifications (seven categories); ethnicity (white/non-white); Government Office Region (GOR) of residence (nine categories); survey year (sixteen categories); number of children (aged 2-15) in household (0,1, 2, 3 or more); number of adults (aged 16+) in household (categorical variable: $1-9)$.

In addition, in the instrumental variable models only, I included the following four variables for the child that was used to generate the instrument: age of the child (1 year dummy variables); gender of the child. In addition, I include two behaviour variables of the child: smoking status of the child $(0=$ never smoked a cigarette, $1=$ have smoked a cigarette, $2=$ =smoking information missing); and, alcohol consumption for the child $(0=$ have never had a proper alcoholic drink, 1 =have had a proper alcoholic drink, $2=$ alcohol information missing). The reason for the inclusion of these variables is discussed below.

The analysis was stratified by gender and I follow earlier studies and restrict the population to individuals aged 30 to 55 (Johansson et al., 2009). The reason for this was that these individuals are most likely to: 1 ) have finished their education, but still be in the labour market (Johansson et al., 2009); 2) have children in the age range 11-25, which were used for the instrumental variable approach. 


\subsection{Instrument}

I follow previous studies and use anthropometric measures of a biological relative as an instrument for measures of body fat (Cawley, 2004, Cawley and Meyerhoefer, 2012, Lindeboom et al., 2010, Kline and Tobias, 2008, Trogdon et al., 2008). The instrument was constructed by matching parents with each child (aged 11-25) with a valid height, weight and/or WC measurements. From this I produce a variable for the oldest child's WC and the oldest child's BMI for each individual aged 30-55. I use two different instruments:

1. WC of the oldest biological child: to instrument WC and obesity defined using WC

2. BMI of the oldest biological child: to instrument BMI and obesity defined using BMI

Importantly, I do not use BMI to instrument WC and vice versa. This means that any error in BMI, e.g. high muscle mass, is not used to predict WC. Thus I have one dependent variable (employment status), four sets of independent variables (WC, BMI, obesity classified using WC and obesity classified using BMI), I run both non-IV and IV models; run regressions in the full population and stratify by sex. In total I run $1 \times 4 \times 2 \times 3$ sets of results. In addition to this, I also display results of models where I include both WC and WC-squared (or BMI and BMI-squared) as explanatory variables.

\subsubsection{The first requirement of an instrument}

The first requirement of an instrument is that it is highly correlated with variables being instrumented conditional on the other variables in the model. The WC and BMI of a biological relative are powerful instruments because roughly half of the variation in weight across people is of genetic origin (Comuzzie and Allison, 1998). To test this I run F-tests to check that the instruments exceeds the benchmark value of $F=10$ (Staiger and Stock, 1997).

\subsubsection{The second requirement of an instrument}

The second requirement of an instrument is that it must not be correlated with the error term in the outcome equation conditional on the other covariates in the model. This will not be fulfilled if both the parent and the child's WC (or BMI) are affected by common household environments that are also directly correlated with the parent's employment status. It is difficult to prove no such effect, however a large number of studies do not 
find any evidence of this (Cawley and Meyerhoefer, 2012, Sørensen et al., 1992, Vogler et al., 1995, Maes et al., 1997). This has further support by findings from the UK (Wardle et al., 2008). In addition, adoption studies find that the correlation between child and biological parents BMI is the same for adoptees as natural children (Vogler et al., 1995), which suggest that variation in weight cannot be attributed to shared household environments.

To further explore this potential issue I run an OLS regression to explore the association between the BMI of parents and their adopted children (N=202). I controlled for the same covariates as explained above. The coefficient value was -0.007 and the t-value was -0.06. I.e. there was no association between parent and child BMI when the child was adopted.

There are also other potential concerns with regards to using genes as instrumental variables. First, the instrument must be independent of all potential outcomes and potential treatments. This might be an issue if the allocation of genes differs by certain socio-demographic characteristics (e.g. ethnicity), and the same characteristics are correlated with the outcome variable. To mitigate this I control for a number of characteristics including region and ethnicity. Another issue might be that genes that affect fat-mass could also affect other characteristics that directly affect employment outcomes, and the genes that affect weight may lie next to genes that directly affect employment outcomes (Norton and Han, 2008, Cawley et al., 2011, Muramatsu and Higuchi, 1995, Guo et al., 2010). If genes that cause obesity are correlated employment outcomes through other channels than through obesity, it will violate the second requirement for an instrument. To mitigate this effect I control for the behavioural health risk variables smoking and alcohol consumption in children, as described above. Although, these variables might not capture all risky health behaviour in children, they might serve as a proxy for other risky health behaviours. I also experiment with models that control for the child's health status. Finally, I include a number of individual control variables. However, like earlier studies that has used this instrument (Cawley, 2004, Cawley, 2000b, Cawley and Meyerhoefer, 2012, Kline and Tobias, 2008, Lindeboom et al., 2010, Cawley et al., 2015, Brunello and d'Hombres, 2007, Cullinan and Gillespie, 
2015, Guettabi and Munasib, 2015) I acknowledge this as limitation, which is important to keep in mind when interpreting the findings.

\section{Analysis and estimation}

I use both multiple probit models, Linear Probability Models (LPM) and IV regression methods to estimate the impact of WC, BMI and measures of obesity on employment outcomes. I model employment outcomes for individual $i$ as:

$Y_{i}=c_{0}+c_{1} B_{i}+X_{i} \gamma+u_{i}$

where $Y$ is a binary measure of employment outcomes; $B$ is a measure of BMI, WC or obesity; and $X$ is a vector of individual, household and child's characteristics. $u$ is an error term and $c$ and $\gamma$ are coefficients to be estimated. My primary models were probit models and Eq. 1 will produce unbiased estimates of $c$ provided there are no endogeneity issues. I perform Hosmer-Lemeshow goodness of fit tests adapted for large samples (Paul et al., 2013). I fail to reject this test in each instance indicating that the probit function is appropriate.

I also use two IV regression methods depending on whether I estimate the impact of WC and BMI as continuous variables or as binary obesity variables. To estimate the impact of WC and BMI as continuous variables I use control functions applied using maximum likelihood estimation. The first stage is estimated by OLS:

$B_{i}=a_{0}+a_{1} Z_{i}+X_{i} \alpha+u_{1 i}$

where $B$ is BMI , $a, b, \alpha$ and $\beta$ are coefficients to be estimated, and $Z$ are instruments that are correlated with $B$ but not $u_{1}$. Based on this model I predict the residuals $\left(\hat{u}_{1 i}\right)$ which is included as a regressor in the second stage multiple probit model:

$Y_{i}^{*}=b_{0}+b_{1} B_{i}+X_{i} \beta+b_{2} \hat{u}_{1 i}+u_{2 i}$

This model makes few distributional assumptions (Terza et al., 2008), however a drawback is that the regressor of interest (in this case WC and BMI) should be 
continuous (Rothe, 2009). Given that the instrument is valid; this model no longer has endogenity problems and an F-test of the residual $\left(b_{2}\right)$ is a direct test of endogeneity. Under the null hypothesis that the dependent variable (WC or BMI) is exogenous the coefficient on the residuals will be zero.

To investigate the impact of obesity as a binary variable I use a recursive bivariate probit model based on the following equations:

$B_{i}=a_{0}+a_{1} Z_{i}+X_{i} \alpha+\mu_{1 i}$

$Y_{i}^{*}=b_{0}+b_{1} \hat{B}_{i}+X_{i} \beta+\mu_{2 i}$

where $B$ is an unobserved latent variable, $a, b, \alpha$ and $\beta$ are coefficients to be estimated, and $Z$ are instruments that are correlated with $B$ but not $\mu_{1}$. The coefficient of interest is $b_{1}$. From these equations the correlation between the error terms in the obesity and employment equations, $\operatorname{Cov}\left[\mu_{1 i}, \mu_{2 i}\right]=\rho$, can be estimated. A Wald test of the significance of $\rho$ is a direct test of the endogeneity of B in the employment equation. The IV regression models use $Z$ to isolate exogenous variation in $B$ and thereby estimate the impact of $B$ on $Y$. The bivariate probit model can be used when both the dependent variable and the endogenous explanatory variable are binary (Woolridge, 2002, Jones, 2007).

I apply survey weights reported in the HSE to each observation. Waist circumference was only measured during the nurse visit, and not all respondents participated in this part of the survey. To use a comparable sample in the BMI regressions I exclude all of those who did not have a nurse visit from the analysis. Hence, in the analysis I have used nurse visit weights to take account of non-response to the nurse section of the survey. The weights adjust for the fact that different observations have different probabilities of participation in the survey and selection for the nurse visit. It is also possible that, due to the sampling strategy used in the HSE, observations are independent across Primary Sampling Units (PSUs), but not within PSUs. I therefore control for clustered sampling within PSUs using unique PSU/year identifiers that produce Huber/White/sandwich robust variance estimators that allow for within-group dependence (Kish and Frankel, 1974). 


\section{Making comparable coefficients}

I computed elasticity's and marginal effects, fixing the covariates at their whole sample mean values. However, to make the continuous coefficients based on WC and BMI comparable I run a second set of regressions with standardized the coefficients for WC and BMI. I standardize the independent variables only (x-standardization), to display the relative importance of WC and BMI. The x-standardized coefficients should be interpreted as the impact of a 1 standard deviation increase in WC or BMI on employment.

Standardized dummy variables makes less sense, hence to quantify the difference in the consequences of defining obesity using WC versus BMI, I computed population attributable fraction (PAF). The PAF is, in theory, the proportion of cases that would be prevented if obesity was eliminated. Hence, I compare the employment outcomes from the same model between different scenarios. The first scenario describes the employment outcomes if all covariates are as observed $\left(p_{0}\right)$. The second scenario describes the employment outcomes if all covariates are as observed except from obesity, which is set to zero $\left(p_{1}\right)$. The PAF can be computed by the following formula:

$$
P A F=\frac{p_{0}-p_{1}}{p_{0}}
$$

Theoretically, the PAF show the percentage change in the employment outcome variable if obesity is eliminated altogether.

\section{Results}

The total number of respondents in the HSE in 1998-2013 (excluding year 2000) was 220,588 . Of these 42,653 were aged $30-55$, had valid height, weight and a nurse visit where waist measurements were conducted. Table 1 displays summary characteristics of the samples. In the IV sample the each individual has a child (aged 11-25), which were used to generate the instrument. Thirty five percent of the full population was obese as defined by WC, while $25 \%$ were obese as defined by BMI. Similar numbers in the IV sample was $39 \%$ and $27 \%$. Compared with the full sample the IV sample has a higher 
mean age, lower share with a degree, more non-white, fewer singles, more adults and children in the household (Table 1). Hence, there were differences across the samples.

The probit models in the full-sample suggests that one standard deviation increase in WC had a greater impact on employment, than one standard deviation increase in BMI, in both men and women (Table 2). In the full-sample we also observe that the elasticities were higher for WC than for BMI. This suggests that, compared with BMI, a $1 \%$ change in WC was associated with a larger shift in probability of employment. The difference, between the impact of WC and BMI, was especially pronounced in men, as the impact of BMI was non-significant and the impact of WC was significant.

Turning to the IV-sample (Table 2), we observe that overall the impact of both BMI and WC were more pronounced, compared with the full-sample. However, a similar pattern as above was observed. I.e. the impact of WC on employment was more pronounced, than the impact of BMI, in both men and women.

Appendix table A.1 show that the instruments are positively associated with both WC and BMI in each model and that the F-values were well above conventional recommendations (exceeds the benchmark value of F=10 (Staiger and Stock, 1997)). Hence, the first requirement for an instrument was fulfilled in each model.

In men the elasticities in the IV models, of the impact of WC and BMI on employment, were larger, compared with the probit models (Table 2). The endogeneity tests were also significant for both WC and BMI in men, suggesting that the probit models underestimate the impact of both WC and BMI on employment. In men the $\mathrm{x}-$ standardized coefficients were now larger for BMI than for WC. In women, a similar pattern emerges, where the x-standardized coefficients were larger for BMI. However, the IV coefficients were not significant in women, nor were the endogeneity tests.

Table 3 display the impact of the binary obesity variables on employment. Similar patterns as for the continuous variables emerge. This means that the impact of obesity, defined by WC, was larger than the impact of obesity defined by BMI. I.e. the fraction of unemployment (PAF) that could be explained by obesity was larger when WC was used 
to define obesity compared with BMI, in both men and women. However, as above this pattern was not supported by the IV-models. The IV-models also suggest significant endogeneity in men for both WC-obesity and BMI-obesity.

While the elasticities reported in Table 2 are informative, they predict the impact of changes in WC and BMI near the mean. This can be misleading if the relationship between fat-mass and employment is non-linear, as suggested for employment and other outcomes like health service use (Roos et al., 2013, Cawley and Meyerhoefer, 2012, Kinge and Morris, 2014). I allow for nonlinearity by including WC squared and BMI squared and run LPM in the IV-sample (Table 4). I also run IV-LPM models ${ }^{b}$, which means that there are two endogenous variables and I need a second instrument. Hence, I follow Wooldridge (2010) and include a squared linear prediction of WC based on the first stage as an additional instrument (Wooldridge, 2010). Based on these models I present x-standardized coefficients (Table 4).

In men, linear WC only seemed to fit the data well, especially in the IV-models (Table 4). However, in women the inclusion of a squared term demonstrated a significant nonlinear impact of WC and BMI on employment. This contrasts the findings in Table 2 and 3 , and suggests that there was an impact of both WC and BMI on employment in women; however it was U- or J shaped. Hence, there was a negative impact both high and low body fat on employment in women.

I also conducted other robustness analyses. First, I ran analyses adjusting for height in each regression. Although height in itself was positively associated with employment, this had negligible impact on the relationship between WC and employment. The coefficients for WC increased slightly, but it did not alter the conclusions. Second, I tried numerous versions of the instrument. I tried to include power terms of WC and BMI of the child and it did not alter the conclusions. I tried instruments where WC of the child was interacted with age and gender of the child. However, it did not alter the findings. Third, I ran analyses excluding children with very high and low BMI. Although the coefficients of the instrumented BMI became weaker, it did not alter the conclusions. Fourth, it ran models with interactions between parent and child variables, which also

\footnotetext{
${ }^{\mathrm{b}}$ These models are estimated using linear two-stage least squares regressions.
} 
did not alter any of the conclusions. Finally, I ran IV-models where I controlled for the health status of the child's that are used to generate the instrument. I controlled for selfassessed health (five categories) and number of longstanding illnesses $(0,1,2,3$ or more). Although the coefficients became weaker it did not alter any of the conclusions and the IV-analysis still showed significant associations between both WC and BMI with employment status.

\section{$\underline{\text { 5. Discussion }}$}

This study demonstrates significant associations between WC and employment in both men and women. A high WC was associated with a lower probability of being employed. However, my findings also suggest that the relationship between WC and employment was non-linear in women, where both high and low body fat has a negative impact on employment. By comparing the impact of WC with the impact of BMI on employment, I found that the consequence of obesity for employment status was larger when WC was used to define obesity than when BMI was used, in both men and women in the multivariate models. However, the IV-models did not support this conclusion and provided relatively similar estimates of the impact of WC and BMI on employment.

My findings from the multivariate models (not IV-models) suggested that fat mass, measured by both WC and BMI was negatively associated with women's probability of being in employment. These results are largely consistent with those of Mosca (2013), Johansson et al. (2009) and Burkhauser and Cawley (2008), who also found negative associations between different measures of body fat and employment in women. And these studies also found more significant associations between continuous measures of body fat and employment in women, compared with men.

My IV-models did not support the finding of a more pronounced effect in women. In the IV-models the association between linear measures of fatness and employment in women was insignificant. This result is comparable to findings by (Cawley, 2000b). Who also found no significant impact of BMI on female labour market limitations, in an instrumental variable model using biological children's BMI as instruments. However, my study further contributes to these findings by demonstrating significant non-linear associations between body fat and employment in women in the IV-models. 
The results for men suggested that the association between linear WC and employment was significant and negative in the multivariate probit models. However, the association between linear BMI and employment was not significant in the probit models. This is similar to Johansson et al. (2009), who found significant negative associations between WC and employment in men. However, their association between BMI and employment was not significant. Analogous findings were also done by Burkhauser and Cawley (2008) when they compared the associations of BMI and percent body fat (measured by BIA) with employment status in men. I.e. BMI was not significant. Mosca (2013) did also not find significant association between BMI and employment in older Irish men. In addition, Mosca (2013) did not find significant associations between linear WC and employment in men.

My findings further contribute to earlier literature in several respects. Firstly, by calculating standardized coefficients and PAF I demonstrate that the impact of WC on employment was larger than when BMI was used to measure fatness, in the non-IV models. Second, I had a large sample size and found significant results of both measures of fatness (WC and BMI), in both men and women. Third, I explored quadratic functions of continuous WC and BMI, and found it to be better at predicting employment probability in women. Fourth, I run IV-regressions, which allows for comparison with earlier IV-studies. Fifth, my finding suggests that the IV-models might mitigate the measurement error of using BMI (based on measures height and weight).

What might account for the finding that the IV-regression methods, using biological children as instruments, might mitigate the measurement error associated with BMI? BMI is criticised for not distinguishing fat from muscle, bone and other lean body mass (Burkhauser and Cawley, 2008). It is body fat that independently predict ill health, thus $\mathrm{BMI}$ introduces noise and as a result BMI overestimates fatness among those who are muscular (Prentice and Jebb, 2001). Although both body fat and muscles might be genetically determined in a similar regard, children and young adults might not have developed muscles yet. As I use children and young adults as instrument, this might mitigate the measurement error related to muscles. In addition, if muscles were less 
genetically determined, than fat, it could explain my findings. However, further research is needed.

When interpreting the findings it is important to recognise that this study has limitations. First, because of the instrument used in the IV models, I was forced to limit the IV-sample to adults with a biological child between the ages of 11-25. As a result the IV-results may not generalize to the entire population. When comparing the results in the IV-population with the results in the full population I observe some differences. Second, it is important to recognise potential limitations regarding the validity of the instruments. The identifying assumption is that weight of a biological child is strongly correlated with the respondent's weight, but uncorrelated with residual employment outcomes. As discussed above, a large literature supports a strong genetic component to weight, and that any similarity in weight due to shared environment is non existing or very small. However, another potential issue is that the genes that are correlated with obesity are also correlated with other behaviour that directly affects residual employment outcomes. A range of control variables are included, however I am not able to control for everything and like previous literature (Kline and Tobias, 2008, Cawley, 2004), I acknowledge this as a potential limitation.

To conclude, the findings of this study suggest that obesity has a negative impact on employment in both men and women. The consequences of obesity for employment were larger when WC was used as a measure of obesity compared with BMI in the nonIV models. Similar findings were not conducted in the instrumental variable models. Although the IV models found significant impacts of obesity on employment, they were not more pronounced when WC was used to measure obesity, compared with BMI. 
Table 1: Summary statistics

\begin{tabular}{|c|c|c|}
\hline & $\begin{array}{l}\text { Full } \\
\text { sample }\end{array}$ & $\begin{array}{l}\text { IV- } \\
\text { sample }\end{array}$ \\
\hline WC (mean) & 91.1 & 91.4 \\
\hline BMI (mean) & 27.3 & 27.7 \\
\hline Obese_WC (\%) & 34.7 & 39.2 \\
\hline Obese_BMI (\%) & 24.6 & 26.8 \\
\hline Age (mean) & 42.7 & 45.1 \\
\hline \multicolumn{3}{|l|}{ Education qualifications (\%) } \\
\hline Degree & 24.4 & 20.0 \\
\hline Higher education below degree & 13.1 & 13.4 \\
\hline GCE A level equivalent & 13.9 & 14.1 \\
\hline GCE 0 level equivalent & 26.7 & 28.5 \\
\hline CSE other grade equivalent & 4.8 & 5.1 \\
\hline Foreign/other & 1.8 & 1.9 \\
\hline No qualification & 15.3 & 17.1 \\
\hline \multicolumn{3}{|l|}{ Ethnicity } \\
\hline Non-white & 9.3 & 11.4 \\
\hline White & 90.7 & 88.6 \\
\hline \multicolumn{3}{|l|}{ Marital status (\%) } \\
\hline Single/divorced & 24.5 & 17.0 \\
\hline Married & 64.2 & 77.2 \\
\hline Cohabiters & 11.3 & 5.9 \\
\hline \multicolumn{3}{|l|}{ Number of children $(\%)^{1}$} \\
\hline 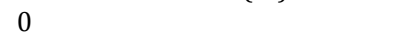 & 53.4 & 36.3 \\
\hline 1 & 20.6 & 31.6 \\
\hline 2 & 19.2 & 23.4 \\
\hline 3 or more & 6.8 & 8.8 \\
\hline \multicolumn{3}{|l|}{ Adults in household (\%) } \\
\hline 1 & 15.7 & 4.8 \\
\hline 2 & 59.5 & 31.2 \\
\hline 3 & 16.8 & 41.5 \\
\hline 4 & 6.7 & 18.7 \\
\hline 5 & 1.2 & 3.3 \\
\hline 6 & 0.2 & 0.4 \\
\hline 7 & 0.0 & 0.1 \\
\hline 8 & 0.0 & 0.0 \\
\hline 9 & 0.0 & 0.0 \\
\hline \multicolumn{3}{|l|}{ GOR of residence $(\%)$} \\
\hline North East & 6.6 & 7.2 \\
\hline North West & 14.2 & 14.6 \\
\hline Yorkshire and The Humber & 10.3 & 11.4 \\
\hline East Midlands & 10.1 & 10.1 \\
\hline West Midlands & 9.8 & 10.0 \\
\hline East of England & 11.1 & 10.7 \\
\hline London & 11.2 & 10.6 \\
\hline South West & 10.2 & 10.2 \\
\hline South East & 16.6 & 15.3 \\
\hline \multicolumn{3}{|l|}{ Survey year (\%) } \\
\hline 1998 & 14.0 & 11.4 \\
\hline 1999 & 1.0 & 0.3 \\
\hline 2000 & NA & NA \\
\hline 2001 & 12.8 & 8.9 \\
\hline 2002 & 6.2 & 4.6 \\
\hline 2003 & 11.5 & 7.8 \\
\hline 2004 & 0.5 & 0.7 \\
\hline 2005 & 5.4 & 7.4 \\
\hline 2006 & 10.1 & 12.9 \\
\hline 2007 & 4.8 & 6.2 \\
\hline 2008 & 9.7 & 12.5 \\
\hline 2009 & 3.1 & 3.7 \\
\hline 2010 & 5.2 & 6.4 \\
\hline 2011 & 5.2 & 5.5 \\
\hline 2012 & 4.8 & 5.3 \\
\hline 2013 & 5.7 & 6.6 \\
\hline
\end{tabular}


Table 2: elasticity (WC and BMI) and x-standardized coefficients based on linear WC and BMI

\begin{tabular}{|c|c|c|c|c|c|c|c|c|c|c|c|c|}
\hline & Full popu & lation & & & Men & & & & Women & & & \\
\hline Probit in full-sample & $\begin{array}{l}\text { Elast. } \\
N=42653\end{array}$ & $z$ & $\begin{array}{l}\text { X-stand. } \\
\text { coef. }\end{array}$ & $\begin{array}{l}\text { Endog. } \\
\text { test }\end{array}$ & $\begin{array}{l}\text { Elast. } \\
N=19119\end{array}$ & $Z$ & $\begin{array}{l}\text { X-stand. } \\
\text { coef. }\end{array}$ & $\begin{array}{l}\text { Endog. } \\
\text { test }\end{array}$ & $\begin{array}{l}\text { Elast. } \\
N=23534\end{array}$ & $z$ & $\begin{array}{l}\text { X-stand. } \\
\text { coef. }\end{array}$ & $\begin{array}{l}\text { Endog. } \\
\text { test }\end{array}$ \\
\hline WC & -0.151 & -7.51 & -0.070 & & -0.065 & -2.36 & -0.035 & & -0.266 & -9.15 & -0.092 & \\
\hline BMI & -0.056 & -3.92 & -0.032 & & -0.012 & -0.57 & -0.008 & & -0.119 & -5.67 & -0.057 & \\
\hline Probit in IV-sample & $N=9391$ & & & & $N=3410$ & & & & $N=5981$ & & & \\
\hline WC & -0.231 & -5.79 & -0.111 & & -0.149 & -2.76 & -0.097 & & -0.298 & -5.23 & -0.107 & \\
\hline BMI & -0.128 & -4.44 & -0.076 & & -0.073 & -1.74 & -0.064 & & -0.173 & -4.20 & -0.085 & \\
\hline \multicolumn{13}{|l|}{ IV-probit* } \\
\hline WC & -0.325 & -2.34 & -0.154 & 0.49 & -0.598 & -3.14 & -0.336 & 0.03 & -0.191 & -1.10 & -0.069 & 0.53 \\
\hline BMI & -0.311 & -2.85 & -0.177 & 0.09 & -0.485 & -3.45 & -0.345 & 0.01 & -0.212 & -1.56 & -0.103 & 0.78 \\
\hline
\end{tabular}

*control function probit

I include the following covariates in each regression: age (quadratic function); gender (in the full population regressions); survey year (sixteen categories); marital status (married/cohabitees/non-married); education qualifications (seven categories); ethnicity (white/non-white); Government Office Region (GOR) of residence (nine categories); number of children in household (0, 1, 2, 3 or more); and, number of adults in household (categorical variable: 1-9). The IV-regressions also include: age of the child (1 year age dummy variables); gender of child; smoking status of child (ever tried cigarettes, yes/no/missing); and, alcohol consumption of child (ever tried alcohol yes/no/missing).

Table 3: marginal effects and population attributable fractions (PAF) from obesity based on WC definition and BMI definition

\begin{tabular}{|c|c|c|c|c|c|c|c|c|c|c|c|c|}
\hline & \multicolumn{4}{|c|}{ Full population } & \multicolumn{4}{|l|}{ Men } & \multicolumn{4}{|l|}{ Women } \\
\hline & $M E$ & $z$ & $P A F$ & $\begin{array}{l}\text { Endog. } \\
\text { test }\end{array}$ & $M E$ & $Z$ & $P A F$ & $\begin{array}{l}\text { Endog. } \\
\text { test }\end{array}$ & $M E$ & $Z$ & $P A F$ & $\begin{array}{l}\text { Endog. } \\
\text { test }\end{array}$ \\
\hline Probit in full-sample & \multicolumn{4}{|l|}{$N=42653$} & \multicolumn{4}{|c|}{$N=19119$} & \multicolumn{4}{|c|}{$N=23534$} \\
\hline Obesity_WC & -0.025 & -6.71 & -0.012 & & -0.016 & -3.75 & -0.007 & & -0.037 & -6.53 & -0.020 & \\
\hline Obesity_BMI & -0.026 & -6.72 & -0.009 & & -0.013 & -2.85 & -0.005 & & -0.044 & -7.13 & -0.016 & \\
\hline Probit in IV-sample & \multicolumn{4}{|l|}{$N=9391$} & \multicolumn{4}{|l|}{$N=3410$} & \multicolumn{4}{|l|}{$N=5981$} \\
\hline Obesity_WC & -0.036 & -4.95 & -0.020 & & -0.024 & -2.97 & -0.013 & & -0.045 & -4.01 & -0.026 & \\
\hline Obesity_BMI & -0.041 & -5.28 & -0.016 & & -0.026 & -3.00 & -0.011 & & -0.053 & -4.39 & -0.020 & \\
\hline \multicolumn{13}{|l|}{ IV-probit* } \\
\hline Obesity_WC & -0.076 & -2.23 & -0.041 & 0.26 & -0.145 & -3.31 & -0.067 & 0.02 & -0.039 & -0.82 & -0.022 & 0.90 \\
\hline Obesity_BMI & -0.134 & -3.11 & -0.048 & 0.05 & -0.159 & -3.65 & -0.056 & 0.01 & -0.113 & -1.81 & -0.040 & 0.36 \\
\hline
\end{tabular}

*recursive bivariate probit

I include the following covariates in each regression: age (quadratic function); gender (in the full population regressions); survey year (sixteen categories); marital status (married/cohabitees/non-married); education qualifications (seven categories); ethnicity (white/non-white); Government Office Region (GOR) of residence (nine categories); number of children in household (0, 1, 2, 3 or more); and, number of adults in household (categorical variable: 1-9). The IV-regressions also include: age of the child (1 year age dummy variables); gender of child; smoking status of child (ever tried cigarettes, yes/no/missing); and, alcohol consumption of child (ever tried alcohol yes/no/missing). 
Table 4: coefficients and z scores from regression including a linear and quadratic WC (BMI)

\begin{tabular}{|c|c|c|c|c|c|c|c|c|c|c|c|c|}
\hline \multirow[b]{3}{*}{$\begin{array}{l}\text { WC } \\
\text { LPM in IV-sample }\end{array}$} & \multicolumn{6}{|l|}{ Men } & \multicolumn{6}{|l|}{ Women } \\
\hline & \multicolumn{3}{|l|}{ Linear } & \multicolumn{3}{|c|}{ Quadratic } & \multicolumn{3}{|l|}{ Linear } & \multicolumn{3}{|c|}{ Quadratic } \\
\hline & $\begin{array}{l}\text { Coef. } \\
N=3410\end{array}$ & $z$ & $\begin{array}{l}\text { Endog. } \\
\text { Test }\end{array}$ & Coef. & $z$ & $\begin{array}{l}\text { Endog. } \\
\text { Test }\end{array}$ & $\begin{array}{l}\text { Coef. } \\
N=5981\end{array}$ & $Z$ & $\begin{array}{l}\text { Endog. } \\
\text { Test }\end{array}$ & Coef. & $Z$ & $\begin{array}{l}\text { Endog } \\
\text { Test }\end{array}$ \\
\hline $\begin{array}{l}\text { WC } \\
\text { WC squared }\end{array}$ & -0.013 & -2.43 & & $\begin{array}{l}0.050 \\
-0.063\end{array}$ & $\begin{array}{l}0.76 \\
-0.96\end{array}$ & & -0.030 & -5.27 & & $\begin{array}{l}0.079 \\
-0.110\end{array}$ & $\begin{array}{l}1.41 \\
-1.96\end{array}$ & \\
\hline IV-regressions* & & & & & & & & & & & & \\
\hline $\begin{array}{l}\text { WC } \\
\text { WC squared }\end{array}$ & -0.050 & -2.43 & 0.06 & $\begin{array}{l}2.543 \\
-2.606\end{array}$ & $\begin{array}{l}1.82 \\
-1.85\end{array}$ & 0.02 & -0.021 & -1.23 & 0.58 & $\begin{array}{l}0.952 \\
-0.972\end{array}$ & $\begin{array}{l}2.55 \\
-2.59\end{array}$ & 0.03 \\
\hline $\begin{array}{l}\text { BMI } \\
\text { LPM in IV-sample }\end{array}$ & & & & & & & & & & & & \\
\hline $\begin{array}{l}\text { BMI } \\
\text { BMI squared }\end{array}$ & -0.008 & -1.32 & & $\begin{array}{l}0.089 \\
-0.097\end{array}$ & $\begin{array}{l}1.7 \\
-1.86\end{array}$ & & -0.025 & -4.35 & & $\begin{array}{l}0.054 \\
-0.080\end{array}$ & $\begin{array}{l}1.27 \\
-1.90\end{array}$ & \\
\hline IV-regressions* & & & & & & & & & & & & \\
\hline $\begin{array}{l}\text { BMI } \\
\text { BMI squared }\end{array}$ & -0.051 & -2.56 & 0.02 & $\begin{array}{l}1.241 \\
-1.313 \\
\end{array}$ & $\begin{array}{l}1.68 \\
-1.73 \\
\end{array}$ & 0.02 & -0.034 & -1.83 & 0.62 & $\begin{array}{l}0.922 \\
-0.971 \\
\end{array}$ & $\begin{array}{l}2.81 \\
-2.89 \\
\end{array}$ & $\begin{array}{l}0.01 \\
0.01 \\
\end{array}$ \\
\hline
\end{tabular}

*the IV-regressions are based on linear model (i.e. an linear probability model) estimated via two-stage least squares (2sls). I include the following covariates in each regression: age (quadratic function); gender (in the full population regressions); survey year (sixteen categories); marital status (married/cohabitees/non-married); education qualifications (seven categories); ethnicity (white/non-white); Government Office Region (GOR) of residence (nine categories); number of children in household (0, 1, 2, 3 or more); and, number of adults in household (categorical variable: 1-9). The IV-regressions also include: age of the child (1 year age dummy variables); gender of child; smoking status of child (ever tried cigarettes, yes/no/missing); and, alcohol consumption of child (ever tried alcohol yes/no/missing).

\section{Appendix 1}

Table A.1: First-stage results of the impact of the instrument on the enogenous variable

\begin{tabular}{|c|c|c|c|c|c|c|}
\hline & WC & & & Obesity_WC & & \\
\hline & OLS Coeff. & $Z$ & F-test & Probit Coeff. & $Z$ & F-test \\
\hline Total & 0.360 & 25.64 & 657.31 & 0.031 & 19.81 & 392.6 \\
\hline Male & 0.307 & 16.24 & 263.64 & 0.031 & 12.45 & 154.92 \\
\hline Female & $\begin{array}{l}0.397 \\
\text { BMI }\end{array}$ & 22.35 & 499.5 & $\begin{array}{l}0.031 \\
\text { Obesity_BMI }\end{array}$ & 16.75 & 280.67 \\
\hline Total & 0.364 & 25.21 & 635.76 & 0.075 & 20.09 & 403.77 \\
\hline Male & 0.307 & 15.76 & 248.36 & 0.075 & 12.18 & 148.29 \\
\hline Female & 0.404 & 20.67 & 427.33 & 0.078 & 17.07 & 291.36 \\
\hline
\end{tabular}

I include the following covariates in the regressions: age (quadratic function); gender (in the full population regressions); survey year (sixteen categories); marital status (married/cohabitees/non-married); education qualifications (seven categories); ethnicity (white/non-white); Government Office Region (GOR) of residence (nine categories); number of children in household (0, 1, 2, 3 or more); number of adults in household (categorical variable: 1-9); age of the child (1 year age dummy variables); gender of child; smoking status of child (ever tried cigarettes, yes/no/missing); and, alcohol consumption of child (ever tried alcohol yes/no/missing).

\section{$\underline{\text { References }}$}

ASGEIRSDOTTIR, T. L. 2011. Do body weight and gender shape the work force? The case of Iceland. Economics \& Human Biology, 9, 148-156.

ATELLA, V., PACE, N. \& VURI, D. 2008. Are employers discriminating with respect to weight?: European Evidence using Quantile Regression. Economics \& Human Biology, 6, 305-329.

AVERETT, S. \& KORENMAN, S. 1996. The Economic Reality of the Beauty Myth. Journal of Human Resources, 31, 304-330.

BJORNTORP, P., FAIRBURN, C. \& BROWNELL, K. 2002. Definition and classification of obesity. Eating disorders and obesity: A comprehensive handbook, 2, 377-381.

BOZOYAN, C. \& WOLBRING, T. 2011. Fat, muscles, and wages. Economics \& Human Biology, 9, 356363.

BRUNELLO, G. \& D'HOMBRES, B. 2007. Does body weight affect wages?: Evidence from Europe. Economics \& Human Biology, 5, 1-19. 
BURKHAUSER, R. V. \& CAWLEY, J. 2008. Beyond BMI: the value of more accurate measures of fatness and obesity in social science research. Journal of health economics, 27, 519-529.

CAWLEY, J. 2000a. Body weight and women's labor market outcomes. National bureau of economic research.

CAWLEY, J. 2000b. An instrumental variables approach to measuring the effect of body weight on employment disability. Health Services Research, 35, 1159.

CAWLEY, J. 2004. The impact of obesity on wages. Journal of Human Resources, 39, 451-474.

CAWLEY, J. 2015. An economy of scales: A selective review of obesity's economic causes, consequences, and solutions. Journal of health economics, 43, 244-268.

CAWLEY, J., HAN, E. \& NORTON, E. C. 2011. The validity of genes related to neurotransmitters as instrumental variables. Health Economics, 20, 884-888.

CAWLEY, J. \& MEYERHOEFER, C. 2012. The medical care costs of obesity: an instrumental variables approach. Journal of health economics, 31, 219-230.

CAWLEY, J., MEYERHOEFER, C., BIENER, A., HAMMER, M. \& WINTFELD, N. 2015. Savings in medical expenditures associated with reductions in body mass index among US adults with obesity, by diabetes status. PharmacoEconomics, 1-16.

CHAN, D. C., WATTS, G. F., BARRETT, P. H. \& BURKE, V. 2003. Waist circumference, waist-to-hip ratio and body mass index as predictors of adipose tissue compartments in men. Qjm, 96, 441-7.

COMUZZIE, A. G. \& ALLISON, D. B. 1998. The search for human obesity genes. Science, 280, 13741377.

CULLINAN, J. \& GILLESPIE, P. 2015. Does Overweight and Obesity Impact on Self-Rated Health? Evidence Using Instrumental Variables Ordered Probit Models. Health economics.

ELOBEID, M. A., DESMOND, R. A., THOMAS, O., KEITH, S. W. \& ALLISON, D. B. 2007. Waist circumference values are increasing beyond those expected from BMI increases. Obesity, 15, 2380-2383.

EVERETT, M. 1990. Let an overweight person call on your best customers? Fat chance. Sales and Marketing Management, 142, 66-70.

FORD, E. S., MAYNARD, L. M. \& LI, C. 2014. Trends in mean waist circumference and abdominal obesity among US adults, 1999-2012. JAMA, 312, 1151-1153.

GARCIA, J. \& QUINTANA-DOMEQUE, C. 2007. Obesity, employment, and wages in Europe. Advances in health economics and health services research, 17, 187-217.

GREVE, J. 2008. Obesity and labor market outcomes in Denmark. Economics \& Human Biology, 6, 350-362.

GUETTABI, M. \& MUNASIB, A. 2015. The Impact of Obesity on Consumer Bankruptcy. Economics \& Human Biology, 17, 208-224.

GUO, G., CAI, T., GUO, R., WANG, H. \& HARRIS, K. M. 2010. The dopamine transporter gene, a spectrum of most common risky behaviors, and the legal status of the behaviors. PLoS one, 5 , e9352.

JANSSEN, I., KATZMARZYK, P. T. \& ROSS, R. 2004. Waist circumference and not body mass index explains obesity-related health risk. American Journal of Clinical Nutrition, 79, 379-384.

JOHANSSON, E., BÖCKERMAN, P., KIISKINEN, U. \& HELIÖVAARA, M. 2009. Obesity and labour market success in Finland: The difference between having a high BMI and being fat. Economics \& Human Biology, 7, 36-45.

JONES, A. M. 2007. Applied econometrics for health economists: a practical guide, Radcliffe publishing.

KELLY, I. R. 2014. Obesity and the Labor Market: Economics and Human Biology Virtual Issue [Online]. Available: http://www.journals.elsevier.com/economics-and-human-biology/virtual-specialissues/obesity-and-the-labor-market/.

KINGE, J. M. \& MORRIS, S. 2010. Socioeconomic variation in the impact of obesity on health-related quality of life. Social science \& medicine, 71, 1864-1871.

KINGE, J. M. \& MORRIS, S. 2014. Association between obesity and prescribed medication use in England. Economics \& Human Biology, 15, 47-55. 
KISH, L. \& FRANKEL, M. R. 1974. Inference from complex samples. Journal of the Royal Statistical Society. Series $B$ (Methodological), 1-37.

KLINE, B. \& TOBIAS, J. L. 2008. The wages of BMI: Bayesian analysis of a skewed treatment-response model with nonparametric endogeneity. Journal of Applied Econometrics, 23, 767-793.

KOMLOS, J., SMITH, P. K. \& BOGIN, B. 2004. Obesity and the rate of time preference: is there a connection? Journal of biosocial science, 36, 209-219.

KRAGELUND, C. \& OMLAND, T. 2005. A farewell to body-mass index? The Lancet, 366, 1589-1591.

LAROSE, S. L., KPELITSE, K. A., CAMPBELL, M. K., ZARIC, G. S. \& SARMA, S. 2016. Does obesity influence labour market outcomes among working-age adults? Evidence from Canadian longitudinal data. Economics \& Human Biology, 20, 26-41.

LEAN, M., HAN, T. \& MORRISON, C. 1995. Waist circumference as a measure for indicating need for weight management. Bmj, 311, 158-161.

LEAR, S., JAMES, P., KO, G. \& KUMANYIKA, S. 2010. Appropriateness of waist circumference and waist-to-hip ratio cutoffs for different ethnic groups. European Journal of Clinical Nutrition, 64, 42-61.

LINDEBOOM, M., LUNDBORG, P. \& VAN DER KLAAUW, B. 2010. Assessing the impact of obesity on labor market outcomes. Economics \& Human Biology, 8, 309-319.

LUNDBORG, P., NYSTEDT, P. \& ROOTH, D.-O. 2014. Body Size, Skills, and Income: Evidence From 150,000 Teenage Siblings. Demography, 51, 1573-1596.

MAES, H. H., NEALE, M. C. \& EAVES, L. J. 1997. Genetic and environmental factors in relative body weight and human adiposity. Behavior genetics, 27, 325-351.

MCLEAN, R. A. \& MOON, M. 1980. Health, obesity, and earnings. American Journal of Public Health, 70, 1006-1009.

MOODY, A. 2014. Adult anthropometric measures, overweight and obesity. The Health and Social Care Information Centre.

MORRIS, S. 2007. The impact of obesity on employment. Labour Economics, 14, 413-433.

MOSCA, I. 2013. Body mass index, waist circumference and employment: Evidence from older Irish adults. Economics \& Human Biology, 11, 522-533.

MURAMATSU, T. \& HIGUCHI, S. 1995. Dopamine transporter gene polymorphism and alcoholism. Biochemical and biophysical research communications, 211, 28-32.

NATIONAL CENTRE FOR SOCIAL RESEARCH AND DEPARTMENT OF EPIDEMIOLOGY AND PUBLIC HEALTH UNIVERSITY COLLEGE LONDON (UCL) 1997 - 2012. Health Survey for England. Colchester, Essex: UK Data Archive

NATIONAL HEART LUNG AND BLOOD INSTITUTE (NHLBI) 2000. The Practical Guide: Identification, Evaluation and Treatment of Overweight and Obesity in Adults. In: NHLBI (ed.).

NG, M., FLEMING, T., ROBINSON, M., THOMSON, B., GRAETZ, N., MARGONO, C., MULLANY, E. C., BIRYUKOV, S., ABBAFATI, C., ABERA, S. F., ABRAHAM, J. P., ABU-RMEILEH, N. M. E., ACHOKI, T., ALBUHAIRAN, F. S., ALEMU, Z. A., ALFONSO, R., ALI, M. K., ALI, R., GUZMAN, N. A., AMMAR, W., ANWARI, P., BANERJEE, A., BARQUERA, S., BASU, S., BENNETT, D. A., BHUTTA, Z., BLORE, J., CABRAL, N., NONATO, I. C., CHANG, J.-C., CHOWDHURY, R., COURVILLE, K. J., CRIQUI, M. H., CUNDIFF, D. K., DABHADKAR, K. C., DANDONA, L., DAVIS, A., DAYAMA, A., DHARMARATNE, S. D., DING, E. L., DURRANI, A. M., ESTEGHAMATI, A., FARZADFAR, F., FAY, D. F. J., FEIGIN, V. L., FLAXMAN, A., FOROUZANFAR, M. H., GOTO, A., GREEN, M. A., GUPTA, R., HAFEZI-NEJAD, N., HANKEY, G. J., HAREWOOD, H. C., HAVMOELLER, R., HAY, S., HERNANDEZ, L., HUSSEINI, A., IDRISOV, B. T., IKEDA, N., ISLAMI, F., JAHANGIR, E., JASSAL, S. K., JEE, S. H., JEFFREYS, M., JONAS, J. B., KABAGAMBE, E. K., KHALIFA, S. E. A. H., KENGNE, A. P., KHADER, Y. S., KHANG, Y.-H., KIM, D., KIMOKOTI, R. W., KINGE, J. M., KOKUBO, Y., KOSEN, S., KWAN, G., LAI, T., LEINSALU, M., LI, Y., LIANG, X., LIU, S., LOGROSCINO, G., LOTUFO, P. A., LU, Y., MA, J., MAINOO, N. K., MENSAH, G. A., MERRIMAN, T. R., MOKDAD, A. H., MOSCHANDREAS, J., NAGHAVI, M., NAHEED, A., NAND, D., NARAYAN, K. M. V., NELSON, E. L., NEUHOUSER, M. L., NISAR, M. I., OHKUBO, T., OTI, S. O., PEDROZA, A., et al. 2014. Global, 
regional, and national prevalence of overweight and obesity in children and adults during 1980-2013: a systematic analysis for the Global Burden of Disease Study 2013. The Lancet.

NHLBI OBESITY EDUCATION INITIATIVE 1998. Clinical guidelines on the identification, evaluation, and treatment of overweight and obesity in adults, National Heart, Lung, and Blood Institute.

NORTON, E. C. \& HAN, E. 2008. Genetic information, obesity, and labor market outcomes. Health Economics, 17, 1089-1104.

O'NEILL, D. 2015. Measuring obesity in the absence of a gold standard. Economics \& Human Biology, $17,116-128$.

O'NEILL, D. \& SWEETMAN, O. 2013. The consequences of measurement error when estimating the impact of obesity on income. IZA Journal of Labor Economics, 2, 1-20.

OFFER, A. 2001. Body weight and self-control in the United States and Britain since the 1950s. Social History of Medicine, 14, 79-106.

PAGAN, J. A. \& DAVILA, A. 1997. Obesity, occupational attainment, and earnings. Social Science Quarterly, 756-770.

PAUL, P., PENNELL, M. L. \& LEMESHOW, S. 2013. Standardizing the power of the Hosmer-Lemeshow goodness of fit test in large data sets. Statistics in medicine, 32, 67-80.

PRENTICE, A. M. \& JEBB, S. A. 2001. Beyond body mass index. Obesity reviews, 2, 141-147.

RENNA, F. \& THAKUR, N. 2010. Direct and indirect effects of obesity on US labor market outcomes of older working age adults. Social science \& medicine, 71, 405-413.

ROOS, E., LAAKSONEN, M., RAHKONEN, O., LAHELMA, E. \& LALLUKKA, T. 2013. Relative weight and disability retirement: a prospective cohort study. Scand J Work Environ Health, 39, 259-267.

ROOTH, D.-O. 2009. Obesity, attractiveness, and differential treatment in hiring a field experiment. Journal of Human Resources, 44, 710-735.

ROTHE, C. 2009. Semiparametric estimation of binary response models with endogenous regressors. Journal of Econometrics, 153, 51-64.

SABIA, J. J. \& REES, D. I. 2012. Body weight and wages: Evidence from Add Health. Economics \& Human Biology, 10, 14-19.

SARLIO-LÄHTEENKORVA, S. \& LAHELMA, E. 1999. The association of body mass index with social and economic disadvantage in women and men. International journal of epidemiology, 28, 445449.

SEIDELL, J. C. 2010. Waist circumference and waist/hip ratio in relation to all-cause mortality, cancer and sleep apnea. Eur J Clin Nutr, 64, 35-41.

SHIMOKAWA, S. 2008. The labour market impact of body weight in China: a semiparametric analysis. Applied Economics, 40, 949-968.

STAIGER, D. \& STOCK, J. H. 1997. Instrumental Variables Regression with Weak Instruments. Econometrica: Journal of the Econometric Society, 557-586.

SØRENSEN, T., HOLST, C. \& STUNKARD, A. J. 1992. Childhood body mass index--genetic and familial environmental influences assessed in a longitudinal adoption study. International journal of obesity and related metabolic disorders: journal of the International Association for the Study of Obesity, 16, 705-714.

TERZA, J. V., BASU, A. \& RATHOUZ, P. J. 2008. Two-stage residual inclusion estimation: addressing endogeneity in health econometric modeling. Journal of health economics, 27, 531-543.

TROGDON, J. G., NONNEMAKER, J. \& PAIS, J. 2008. Peer effects in adolescent overweight. Journal of health economics, 27, 1388-1399.

VILLAR, J. G. \& QUINTANA-DOMEQUE, C. 2009. Income and body mass index in Europe. Economics \& Human Biology, 7, 73-83.

VOGLER, G. P., SØRENSEN, T., STUNKARD, A. J., SRINIVASAN, M. \& RAO, D. 1995. Influences of genes and shared family environment on adult body mass index assessed in an adoption study by a comprehensive path model. International journal of obesity and related metabolic disorders: journal of the International Association for the Study of Obesity, 19, 40-45.

WADA, R. \& TEKIN, E. 2010. Body composition and wages. Economics \& Human Biology, 8, 242-254. 
WARDLE, J., CARNELL, S., HAWORTH, C. M. \& PLOMIN, R. 2008. Evidence for a strong genetic influence on childhood adiposity despite the force of the obesogenic environment. The American journal of clinical nutrition, 87, 398-404.

WHO 2000. Obesity: preventing and managing the global epidemic. Report of a WHO Consultation. WHO Technical Report Series 894. World Health Organization Geneva.

WOOLDRIDGE, J. M. 2010. Econometric analysis of cross section and panel data, MIT press.

WOOLRIDGE, J. M. 2002. Econometric analysis of cross section and panel data. Cambridge, ma: mit Press.

WORLD HEALTH ORGANIZATION 1995. Physical status: The use of and interpretation of anthropometry, Report of a WHO Expert Committee. 